\title{
Interacting with Digital Memorials in a Cemetery: Insights from an Immersive Practice
}

\author{
Cristiano Maciel, Vinicius \\ Carvalho Pereira \\ Universidade Federal de Mato Grosso \\ Cuiabá - MT - Brazil \\ \{crismac;viniciuscarpe\}@gmail.com
}

\author{
Carla Leitão \\ Pontifícia Universidade \\ Católica do Rio de Janeiro \\ Rio de Janeiro - RJ - Brazil \\ cfaria@inf.puc-rio.br
}

\author{
Roberto Pereira \\ Universidade Federal do \\ Paraná \\ Curitiba - PR - Brazil \\ robertop.ihc@gmail.com
}

\author{
José Viterbo \\ Universidade Federal \\ Fluminense \\ Niterói - RJ - Brazil \\ viterbo@ic.uff.br
}

\begin{abstract}
This research analyzes how users that are also HCI designers behave in the interaction with digital memorials linked to graves through QRCodes. We carried out an immersive practice in the Consolação Cemetery (São Paulo, Brazil), where QRCodes are used to tag graves of famous deceased people and to guide the visitors in the site. The QRCode tags link the graves to an online application for digital memorials called MemoriAll. This paper presents an overview of the study and its main results, promoting discussion on the topic.
\end{abstract}

\section{Palavras Chave}

Memoriais Digitais; Cemitérios; Prática Imersiva; Usuário.

\section{ACM Classification Keywords}

Human-centered computing Social networking sites.

\section{INTRODUCÃO}

No escopo de pesquisa em interação e dados sobre legado digital e pós-morte, tem-se percebido uma mudança nos padrões de construção e manutenção de túmulos em cemitérios, bem como na sua visitação [4]. Além dos visitantes que buscam rememorar ou homenagear parentes, amigos e outras pessoas próximas, nota-se nesses espaços a visitação voltada para fins turísticos. Há, por exemplo, visitantes interessados na arte tumular contida nestes espaços; visitantes que buscam sepulturas de pessoas famosas, as quais atuam como instrumento de preservação da memória cultural particular e coletiva dos indivíduos de um grupo social, entre outros. Em alguns países, a visitação aos cemitérios faz parte do roteiro histórico [1] como por exemplo no Père-Lachaise, em Paris/França, e no cemitério da La Recoleta, em Buenos Aires/Argentina, evidenciando oportunidades para o uso de tecnologias computacionais interativas para apoiar tais atividades.

\footnotetext{
Permission to make digital or hard copies of all or part of this work for personal or classroom use is granted without fee provided that copies are not made or distributed for profit or commercial advantage and that copies bear this notice and the full citation on the first page. Copyrights for components of this work owned by others than the author(s) must be honored. Abstracting with credit is permitted. To copy otherwise, or republish, to post on servers or to redistribute to lists, requires prior specific permission and/or a fee. Copyright 2018 SBC.
}

IHC 2018, Anais Estendidos do XVII Simpósio Brasileiro sobre Fatores Humanos em Sistemas Computacionais

Outubro 22-26, 2018, Belém, Brasil

Artigos Internacionais
A mediação tecnológica na visita a esses espaços pode permitir experiências ampliadas para além da interação imediata com os objetos físicos. De posse de simples dispositivos móveis pode-se permitir, por exemplo, que o visitante do cemitério acesse informações sobre falecidos ou obras de arte tumulares disponibilizadas por meio de QRCodes (Quick Response Code, é um código visual bidimensional que pode ser escaneado por dispositivos móveis equipados com câmera, sendo convertido em texto, endereço URI, número de telefone, localização, etc. Cann [2] argumenta que QRcodes “transferem os mortos do cemitério para o reino dos vivos" ao proporcionarem uma ligação das pessoas vivas com os falecidos, acessível de qualquer lugar. Em geral, os QRCodes em cemitérios dão acesso a memoriais digitais nos quais podem ser encontradas informações sobre falecidos, podendo haver uma interligação entre o mundo físico (localização do túmulo) e o virtual. No Brasil, essa é uma iniciativa ainda muito tímida, porém em outros países, como no Japão e na China, o uso de QRCodes em cemitérios já é uma realidade mais difundida.

Memoriais digitais na Web permitem prestar homenagens a pessoas falecidas, podendo ser considerados um tipo específico de software que pode ser modelado de diferentes maneiras [3] e que tem atraído a atenção de empresas, em especial do ramo funerário. Por ser uma categoria relativamente nova e diferenciada de software, estudos sobre o uso e impacto de memoriais digitais se fazem necessários.

Assim, questiona-se: a produção de tais sistemas tem atendido às expectativas dos usuários? Como os projetistas da Interação Humano-Computador (IHC) percebem tais sistemas? Nesse sentido, esta pesquisa analisa as percepções de projetistas da IHC enquanto usuários de memoriais digitais interligados a túmulos via tecnologia QRCode. Uma prática imersiva no Cemitério da Consolação de São Paulo foi conduzida para propiciar aos projetistas a experiência da visita aos túmulos ampliada por uso de QRcode para o acesso a memoriais das pessoas ali enterradas. O cemitério também disponibiliza totens com QRcode para o visitante se guiar nas ruas e ir em direção aos túmulos, onde, além de obras de arte tumular, podem ser encontradas as lápides de personalidades brasileiras famosas, como Tarsila do Amaral, Monteiro Lobato, Mário de Andrade e a Marquesa de Santos. De forma geral, ao chegar a um túmulo é possível acessar o perfil do 
falecido, via QRcode, no aplicativo chamado "Memoriall", O perfil dispõe de campos para informações como biografia, árvore genealógica, fotos, mensagens, vídeos, obituário etc.

A prática imersiva ocorreu durante a sétima edição do Workshop sobre Aspectos da IHC para a Web Social (WAIHCWS) realizado no Simpósio Brasileiro sobre Fatores Humanos em Sistemas Computacionais (IHC), em São Paulo. Tal edição promoveu o debate sobre as oportunidades e os desafios que a Web Social traz para a comunidade de pesquisa em IHC no contexto do legado digital. Entre outras atividades, os organizadores do workshop propuseram a realização deste estudo exploratório qualitativo, de forma a articular discussões teóricas e atividades práticas relacionadas ao domínio em foco. Assim, 21 participantes do workshop deslocaram-se juntamente com os 4 organizadores da atividade até o Cemitério da Consolação, a fím de participar da prática. Os resultados desta prática foram publicados no artigo [4], sendo analisados os dados coletados via questionários aplicados ao final da prática, com vistas a discutir a problemática definida.

\section{RESULTADOS E CONSIDERAÇÕES FINAIS}

A experiência permitiu a análise das percepções de usuários, experientes em design da interação, quanto ao uso de memoriais digitais interligados a túmulos via tecnologia QRCode. Além de verificar a satisfação desses usuários com o sistema e as possíveis melhorias a este, os resultados ofereceram contribuições interessantes à área.

Entre os principais resultados, pôde-se identificar que, pelo fato de as aplicações thanatosensitivity fazerem parte de uma área nova e diferente, o levantamento de requisitos centrados no usuário é essencial. Práticas imersivas que permitem a coleta de requisitos in loco e usando da computação ubíqua tendem a possibilitar análises mais profundas e enriquecidas pelo entendimento cultural situado da prática. Essas práticas podem ser utilizadas em conjunto com técnicas para elicitação de requisitos de maneira a obter melhores resultados. No experimento citado, foi realizada uma análise semiótica das interfaces do Memoriall.

Entre as lições aprendidas está a necessidade de um planejamento cuidadoso do estudo como um todo, uma vez que uma prática realizada em ambiente externo pode sofrer influência de muitos fatores e possuir riscos que precisam ser antecipados. A realização de teste piloto da estratégia é fundamental para identificar e contornar possíveis problemas. A metodologia conduzida neste estudo pode ser apontada como um possível caminho.

Um dos problemas evidenciados foi a falta de informações nos perfis dos falecidos. A priori, como eles não são inseridos colaborativamente e dependem da alimentação de outrem (família ou empresa que administra o software), e há falta de informações. Outro problema é a arquitetura da informação, que prejudica a navegabilidade e o acesso às informações em dispositivos móveis. Certamente testes de usabilidade e/ou comunicabilidade ajudariam na melhoria dos problemas existentes. Também, a possibilidade de integração destes sistemas com outras ferramentas poderia agregar valor aos memoriais.

Embora os resultados dessa pesquisa ofereçam insumos aos projetistas de aplicações para memoriais digitais na elicitação de requisitos, há necessidade de uma reflexão sobre o impacto de tais aplicações. Nesse sentido, o estudo das percepções dos usuários, bem como de suas práticas e costumes em espaços cemiteriais, permite um melhor entendimento desse domínio com vistas à modelagem de soluções centradas nas necessidades dos usuários.

Para os pesquisadores entusiastas das tecnologias, surge na automação de cemitérios um interessante mercado, que requer atenção. Além dos dados dos falecidos, como evidenciado pelos usuários nesta pesquisa, as artes tumulares podem ser analisadas. Com as possibilidades de cremação e/ou guarda do corpo físico por tempo limitado em determinados cemitérios, há nos memoriais digitais uma maneira de imortalização desses falecidos.

Como pesquisas futuras decorrentes deste trabalho, há a possibilidade da análise de outras fontes de coletas de dados, como fotos e áudios capturados durante a prática, e a realização de uma Inspeção Semiótica da ferramenta. Esses dados podem ser aliados à análise da prática imersiva apresentada neste artigo, com vistas à formulação de um conjunto de guidelines ou requisitos úteis a esta área. Também carecem de análise a interface Web do sistema, na qual se podem contratar os serviços da empresa, adquirindo uma Tag Memoriall, e também prestar homenagens para falecidos, como por exemplo, acendendo uma vela.

\section{REFERÊNCIAS}

1 Thiago. N. Araújo, 2006. Túmulos celebrativos de Porto Alegre: múltiplos olhares sobre o espaço cemiterial (18891930). EdiPUCRS.

2 Candi K. Cann. 2013. Tombstone Technology: Deathcapes in Asia, the U.K.and the U.S. In Maciel, C.; Pereira, V. C., Digital Legacy and Interaction: Post-Mortem Issues. 1. ed. Switzerland: Springer. HCI. 101-113.

3 Aron D. Lopes, Cristiano Maciel, Vinícius C. Pereira. 2014 Recomendações para o design de memórias digitais na web social. In Proc. 13th Brazilian Symp. on Human Factors in Computing Systems. SBC, 2014. p. 275-284.

4 Cristiano. Maciel, Vinícius. C. Pereira, Carla. Leitao, Roberto Pereira and José. Viterbo, 2017.Interacting with Digital Memorials in a Cemetery: Insights from an Immersive Practice. In Proceedings of the 2017 Federated Conference on Computer Science and Information Systems, vol. 11, pp. 1239-1248. http://dx.doi.org/10.15439/2017F337

\footnotetext{
${ }^{1}$ http://memoriall.com.br/
} 